\title{
Unicystic plexiform ameloblastoma: An unusual case report
}

\author{
Meghana HC ${ }^{1 *}$, Sri Charan KN², Pramod GV ${ }^{3}$, Ashok L ${ }^{4}$, Vidya Holla \\ ${ }^{\mathbf{1}}$ Assistant Professor, ${ }^{\mathbf{2}}$ Associate Professor, ${ }^{\mathbf{3}}$ Professor, ${ }^{\mathbf{4}}$ Professor and HOD, ${ }^{\mathbf{5}}$ Assistant Professor, ${ }^{\mathbf{1}, 3,4,5}$ Dept. of Oral Medicine \& Radiology, \\ ${ }^{2}$ Dept. of Internal Medicine, A J Institute of Dental Sciences, Karnataka, India
}

*Corresponding Author: Meghana HC

Email: megnagowda@gmail.com

\begin{abstract}
Ameloblastoma is a benign odontogenic neoplasm which frequently affects the mandible. The term ameloblastoma includes several clinicoradiological and histological types. Unicystic ameloblastoma is a less common type of ameloblastoma. Unicystic ameloblastoma has many clinical, gross features and radiographic features similar to a jaw cyst but on histologic examination shows a typical ameloblastomatous epithelium lining the cyst cavity, with or without luminal and/or mural tumor proliferation. Since there is lot of confusion between unicystic ameloblastoma and dentigerous cyst, the biologic behaviour of this tumor group was reviewed. Since recurrence of a tumor can occur over a delayed period of life, regular follow up is essential in management. Hereby we report an unusual case of unicystic ameloblastoma in a 50-year-old female patient.
\end{abstract}

Keywords: Unicystic, Ameloblastoma, Odontogenic neoplasm.

\section{Introduction}

Ameloblastoma is the most common cause for the development of mandibular swelling. This develops from epithelial cellular elements and dental tissues in their various phases of development. ${ }^{1}$ Classic solid/multicystic ameloblastoma, desmoplastic ameloblastoma, peripheral ameloblastoma, unicystic ameloblastoma are the different subtypes of ameloblastomas. ${ }^{2}$ Among the peripheral ameloblastoma, most of the ameloblastomas are solid or multicystic variants, about $20 \%$ of the cases are with unicystic ameloblastoma. ${ }^{1}$ Much confusion stems from the fact that a unicystic ameloblastoma may appear not only as a unilocular but also as a multilocular bone defect. ${ }^{3-5}$

The unicystic ameloblastoma (UA) has no sexual or racial predilection, more commonly seen between 2030years of age. Patient tend to neglect it since it is asymptomatic and most common location being posterior mandible. Treatment for ameloblastoma ranges from en block excision to curettage depending on histology and clinical presentation of the tumour. ${ }^{6}$ Herby we report an unusual case of unicystic ameloblastoma in a 50-year-old female patient.

\section{Case Report}

A 50 year old female patient was referred to the outpatient department of Bapuji dental college and hospital, Davangere, Karnataka with a complaint of right side facial swelling since 1 month. Swelling was insidious in onset, slowly progressing; initially it was very small in size, reached to present size in 1 month. No history of pain was present. No pus discharge present. No numbness or paresthesia present. Patient denied application of any topical medication over the swelling region. On extra oral examination, a solitary swelling was present over the right lower $1 / 3^{\text {rd }}$ of the face, over the posterior mandibular region, size ranging about $3 \times 4 \mathrm{~cm}$, diffusely spread, colour of the skin over the swelling was normal, extending superio inferiorly from line joining angle of mouth to tragus extending $4 \mathrm{~cm}$ beyond. On palpation it was firm in consistency, non compressible, no pulsation was present [Fig. 1a]. On general physical examination temperature was febrile, on lymph node examination solitary right submandibular lymph node was enlarged, roughly oval in shape measuring $1.5 \mathrm{~cm} \mathrm{X} 1 \mathrm{~cm}$, palpable, mobile, tender, firm in consistency.

On intra oral examination, a solitary diffuse swelling was present over the right mandibular posterior teeth region, size ranging about $3 \times 4 \mathrm{~cm}$, colour appeared normal, extending anterio-posteriorly from mesial of 83 to distal of 47, medio-lateral expansion was seen. On palpation, consistency was firm anteriorly, hard posteriorly, thinning of cortex was evident, nontender on palpation and it was non compressible. On hard tissue examination, there was over retained 83 which was attrited and 44, 45, 46, 47 were tender on percussion. Grade I mobility was present i.r.t 44, 45, 46, 47. [Fig. 1b].

On fine needle aspiration, yellow straw colored fluid with tinge of blood was aspirated. Benign lesion involving the right body of mandible was suspected. Clinical differential diagnosis of Ameloblastoma of right body of mandible, Dentigerous cyst involving missing 43, Odontogenic Keratocyst involving the right body of mandible was given.

OPG revealed over retained 83 , impacted 43 . OPG also shows a solitary mixed radiolucency at the periapical region of $44,45,46,47$, size ranging approximately about $3 x 4 \mathrm{~cm}$, well defined, except for superior border which was scalloping between the roots of teeth, with scalloping on distal aspect of 83, non corticated except for inferior border where it was corticated, thinning of cortex was evident. Internal structure showed septae at superior border, resorption of distal apical $1 / 3^{\text {rd }}$ of root of 46 , displacement of 47 was evident. For better resolution IOPA radiographs were taken and it revealed the same (Fig. 2a, 2b, 2c).

Mandibular right lateral occlusal radiograph showing buccal and lingual cortical plate expansion extending from 
44 to 47 with size ranging about $3 \times 4 \mathrm{~cm}$, with multiple locules of various sizes appreciated with thinning of buccal cortical plate was evident.

Segmental resection of mandible from 83 to 47 , followed by reconstruction of mandible with iliac crest graft was done under general anesthesia. Final diagnosis of Unicystic Plexiform ameloblastoma was made after the histopathological examination of excised specimen [Fig. 3]. Postoperative photographs and OPG were taken. Primary bone grafting with plate fixation of the surgical defect was appreciated in the OPG following the resection of ameloblastoma. [Fig. 4a \& 4b]

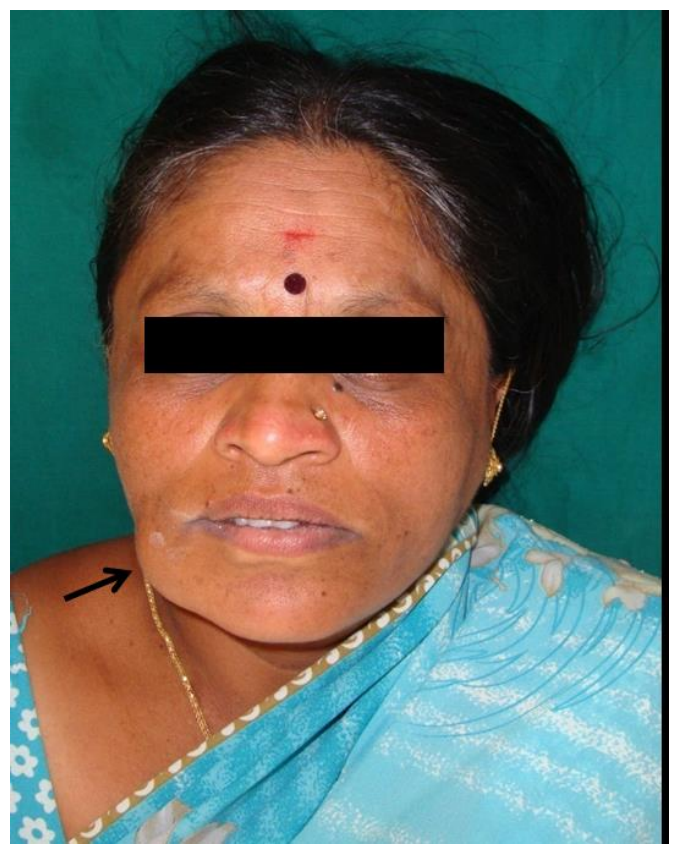

Fig. 1a: Swelling over right side of the mandible

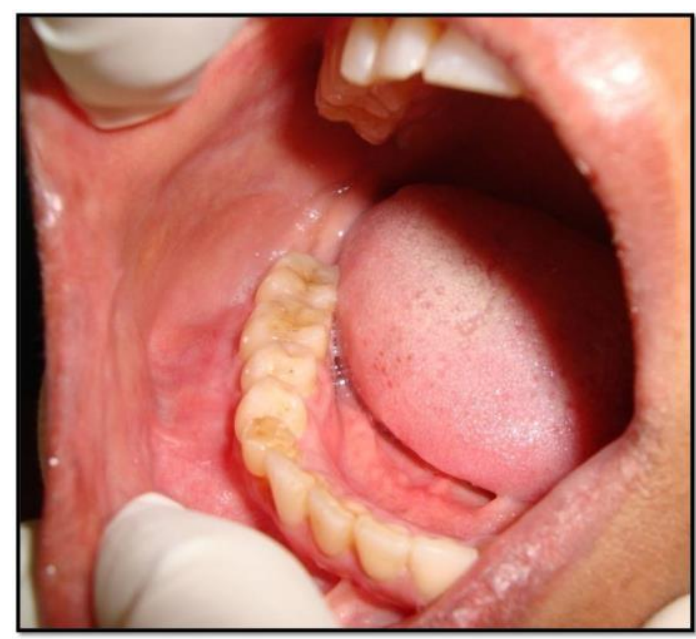

Fig. 1b: Intra oral photograph

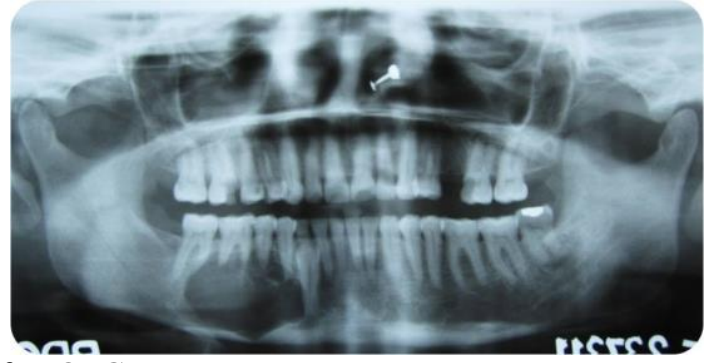

Fig. 2a: OPG
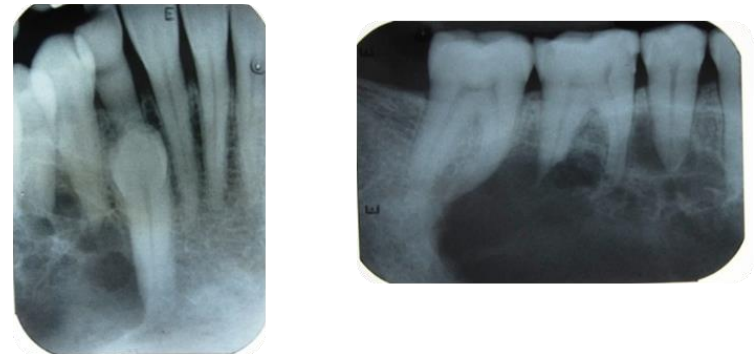

Fig. 2b: IOPA radiographs

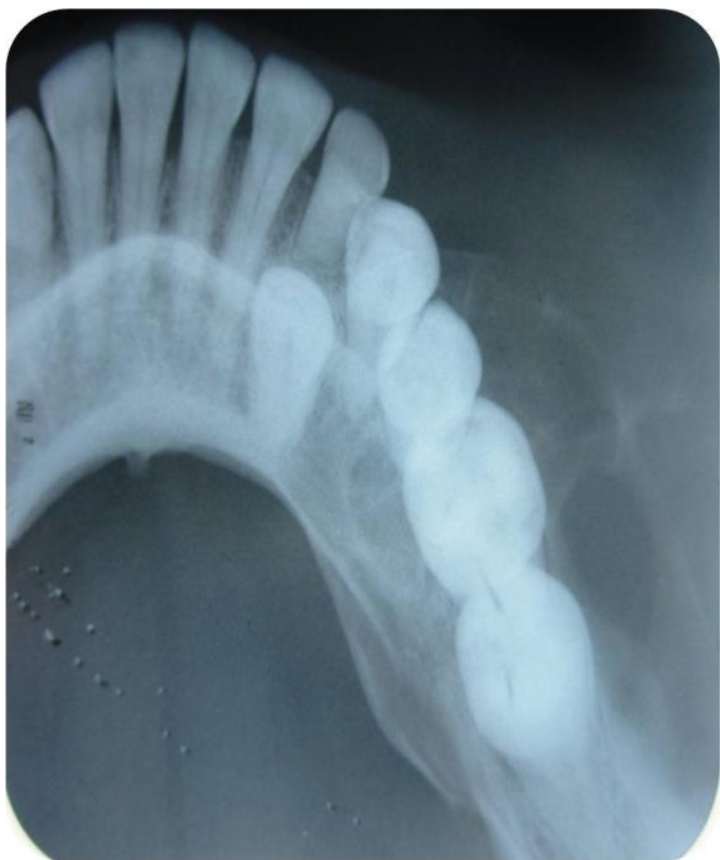

Fig. 2c: Mandibular right lateral occlusal radiograph 


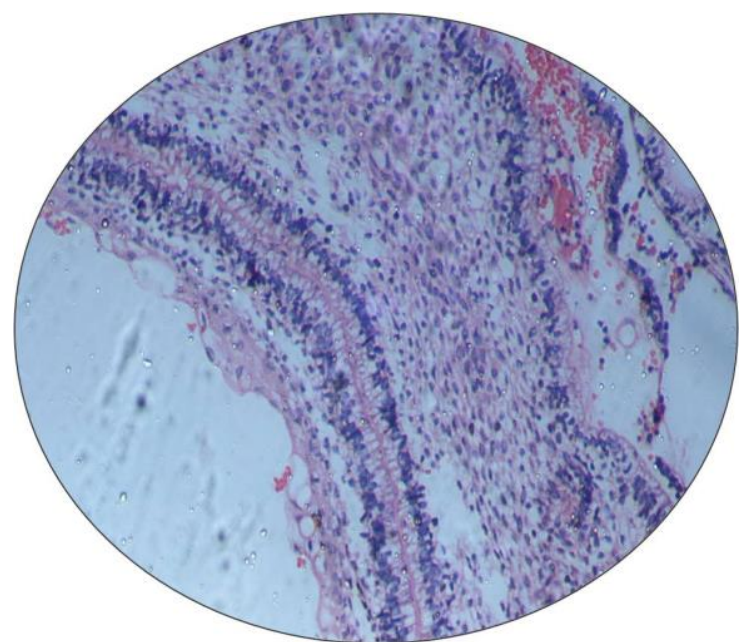

Fig. 3: Histopathologic photograph

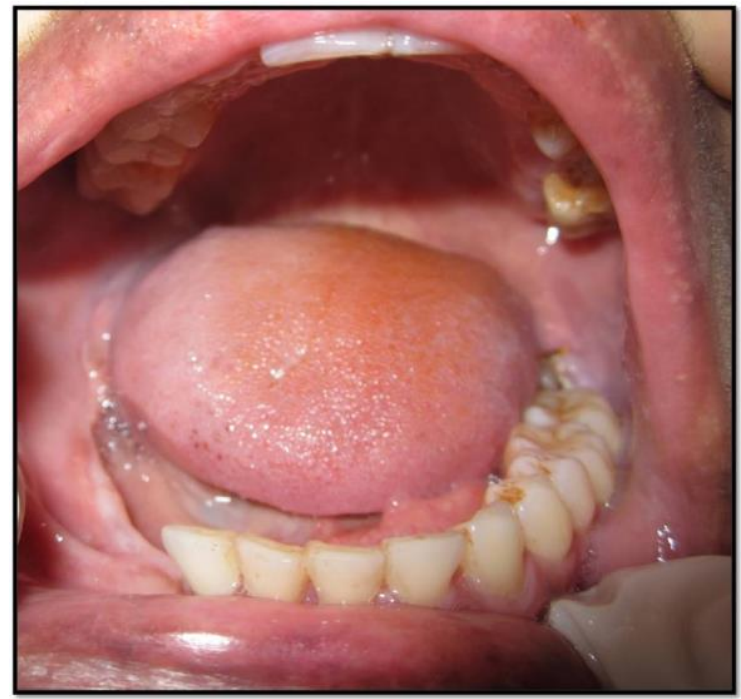

Fig. 4a: Post-Operative Photograph

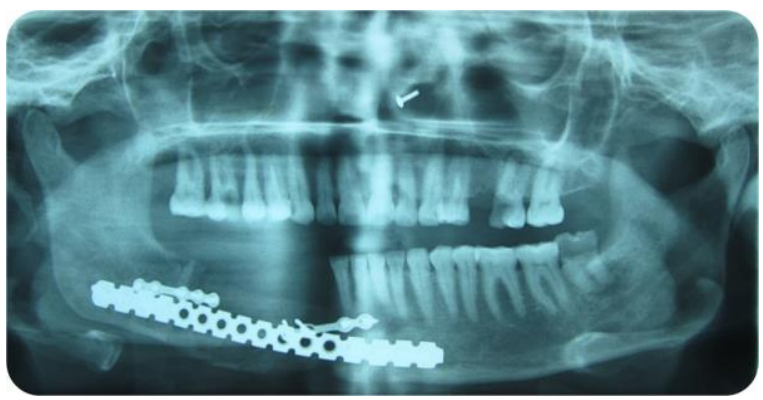

Fig. 4b: Post-operative radiograph

\section{Discussion}

Asymptomatic swelling or expansion of the jaw is the usual clinical presentation of unicystic ameloblastomas. It can grow to any massive proportions. Pain \& parasthesia are usually uncommon. The incidence of unicystic ameloblastoma has been reported as between $5 \%$ to $22 \%$ of all types of ameloblastomas (Reichart et al, 1995). ${ }^{7}$ Robinson and Martinez in 1977 were the first to describe unicystic ameloblastoma and to call for recognition of the entity. Plexiform unicystic ameloblastoma is a relatively rare variant of unicystic ameloblastoma. ${ }^{8}$ UAs usually associated with $2^{\text {nd }}-3^{\text {rd }}$ decade of life. ${ }^{1}$ In contrast to this finding, the present case of dentigerous type of UA was seen in $5^{\text {th }}$ decade of life.

It has been suggested that it arises from a result of neoplastic transformation of the epithelial lining of dentigerous cyst or any other type of dental cyst. ${ }^{9}$ The relatively younger age at occurrence, the unilocular radiographic appearance, the macroscopically cystic nature and most importantly, the better response to conservative treatment, make it a distinguishable entity of UAs. ${ }^{10}$ The predominant location of occurrence of UA is posterior mandible. The mandible: maxilla ratio being 13:1,11 Lip numbness and discharge or drainage in cases of secondary infection is a common finding. High percentage of these lesions are associated with impacted tooth. ${ }^{12}$

Radiographically, UAs have been divided into two main patterns: Unilocular and multilocular. UAs have clear preponderance for the unilocular pattern. The radiological features of UA are typically unilocular and there is a round area of radiolucency. Therefore this lesion is often misdiagnosed as an OKC/a or dentigerous cyst. Eversole et al., identified predominant radiographical patterns for UA: Unilocular, scalloped, macromultilocular, pericoronal, interradicular, or periapical expansile radiolucencies. ${ }^{13}$ Diffuse border of lesion may appear, representing less favorable tissue response or faster growth. Cortical bone expansion with frequent perforations but without any signs of clinical or histopathological neoplastic growth are seen. It causes adjacent root resorption.

\section{Radiographic differential diagnosis}

Dentigerous cysts, odontogenic keratocyst, other simple odontogenic cysts like residual cysts, adenomatoid odontogenic tumour, giant cell lesions and sometimes solid ameloblastoma can be the possible differential diagnoses for a unilocular lesion with or without a 'dentigerous' relationship occurring within the jaws. However, keratocyst seldom shows cortical expansion, residual cysts are associated with missing teeth that have been extracted, adenomatoid odontogenic tumour has a predilection for anterior maxilla, central giant cell granuloma often arises anterior to first mandibular molar and solid ameloblastoma is seen uncommonly in patients less than 30 years of age. ${ }^{14}$

Immunocytochemical markers for lectins (Ulex europaeus agglutinin $\mathrm{I}$ and Bandeiraea simplicifolia agglutinin I) and proliferating cells (proliferating cell nuclear antigen- PCNA and Ki-67) may be helpful in differentiating UA from any other cyst. ${ }^{15}$

Enucleation of the cystic type of UAs is probably adequate for the luminal and intraluminal/ plexiform types. Treatment of the mural type is controversial with some surgeons believing that local resection is best. Late recurrence following treatment is commonly seen, the average interval for recurrence being 7 years. $10-20 \%$ recurrence after enucleation and curettage with all unicystic ameloblastoma is expected. 


\section{Conclusion}

Unicystic Ameloblastoma is an asymptomatic condition manifested with slow growing swelling in the posterior mandibular region. Therefore it should be included in the differential diagnosis when the patient comes to the clinic with swelling, though it is a rare condition. As unicystic ameloblastoma is generally cystic, well localized and surrounded by fibrous capsule, at an earlier diagnosis, tumor can be treated conservatively with less chance of recurrence. However patient must be followed up for ten years as recurrences become apparent after many years of treatment.

\section{Source of funding}

None.

\section{Conflict of interest}

None.

\section{References}

1. Philipsen HP, Reichart PA. Unicystic ameloblastoma. A review of 193 cases from the literature. Oral Oncol 1998;34(5):317-25.

2. Deore SS, Dandekar RC. Plexiform Unicystic Ameloblastoma: A Rare Variant of Ameloblastoma. Case Rep Dent 2014:1-6.

3. Gupta SS, Mhaske S. Unicystic Ameloblastoma presenting as Multilocular Lesion: A Case Report. People's J Sci Res 201;4(2):55-7.

4. Eversole, LR, Leider, AS, Strub, D. Radiographic characteristics of cystogenic ameloblastoma. Oral Surg, Oral Med Oral Pathol 1984;57:572-7.

5. Li TJ, Wu YT, Yu SF, Yu GY: Unicystic ameloblastoma: A clinicopathological study of 33 chinese patients. The Am J Surg Pathol 2000;24(10):1385-92.

6. Paikkatt VJ, Sreedharan S, Kannan VP. Unicystic ameloblastoma of the maxilla: A case report. J Indian Soc Pedod Prev Dent 2007;106-10. DOI: 10.4103/09704388.33459
7. Reichart PA, Philipsen HP, Sonner S. Ameloblastoma: Biological profile of 3677 cases. Eur J Cancer 1995;31B(2):86-99.

8. Iordanidis S, Makos C, Dimitrakopoulos J, Kariki H. Ameloblastoma of the maxilla. Case report. Aust Dent J 1999;44(1):51-5.

9. Leider AS, Eversole LR, Barkin ME. Cystic ameloblastoma: a clinicopathologic analysis. Oral Surg, Oral Med, Oral Pathol 1985;60(6):624-30.

10. Covani U, Barone A. Piezosurgical Treatment of Unicystic Ameloblastoma. J Periodontol 2007;78(7): 1342-7.

11. Reichart PA, Philipsen HP. Unicystic ameloblastoma. Odontogenic tumors and allied lesions. Quintessence Publication. 2004;1:77- 86.

12. Adeyeme WL, Bamgbose BO, Ladeinde AL, Ogunlewe MO. Surgical management of ameloblastomas: conservative or radical approach? A critical review of the literature. Oral Surg 2008;1(1):22-7.

13. Eversole LR, Leider AS, Strub D. Radiographic characteristics of cystogenic ameloblastoma. Oral Surg Oral Med Oral Pathol 1984;57(5):572-7.

14. Langlais RP, Langland OE, Nortgé CJ. Diagnostic Imaging of the Jaws, Williams \& Wilkins, Malvern, Pa, USA, 1st edition, 1995

15. Saku T, Shibata Y, Koyama Z, Cheng J, Okabe H, Yeh Y. Lectin histochemistry of cystic jaw lesions: an aid for differential diagnosis between cystic ameloblastoma and odontogenic cysts. J Oral Pathol Med 1991;20(3):108-13.

How to cite this article: Meghana HC, Sri Charan KN, Pramod GV, Ashok L, Holla V. Unicystic plexiform ameloblastoma: An unusual case report. Int J Maxillofac Imaging 2019;5(3):63-6. 